\title{
Are We Social Prisoners?
}

\author{
Mahendar Kumar \\ Management Science Department, Greenwich University, Karachi, Pakistan \\ Email: mahendarkumar580@gmail.com
}

How to cite this paper: Kumar, M. (2020) Are We Social Prisoners? Open Journal of Social Sciences, 8, 29-50.

https://doi.org/10.4236/jss.2020.81003

Received: December 4, 2019

Accepted: January 3, 2020

Published: January 6, 2020

Copyright (c) 2020 by author(s) and Scientific Research Publishing Inc. This work is licensed under the Creative Commons Attribution International License (CC BY 4.0).

http://creativecommons.org/licenses/by/4.0/

\begin{abstract}
This study is carried out to understand the social prison and social prisoner phenomenon in Pakistan. The concept of social prison has been analyzed in terms of Material Acquisitions (M.A), Social Status Quo (S.S.Q), Social Envy (S.E) and Social Rituals (S.R). The researchers assert the notion of social prison through this study and argue that, individuals are living in the $21^{\text {st }}$ century a life of a social prisoner because, they constantly dwell in a state of ever-lasting quest for material acquisitions, maintaining social status quo, becoming victim of social envy (knowingly or unknowingly) and social rituals. The study is conducted quantitatively and it is based on post-positivist philosophy. However, the sample size is only $170+$ respondents and the convenience sampling technique is used because, this is the kind of research, that is peculiar in nature so, only those respondents are added doing the job presently. The researcher found weak relationship between each of the independent variables (M.A, S.S.Q, S.E and S.R) and the dependent variable (Social prisoner phenomenon in Pakistan). Consequently, it was found in the end that, there is a moderate relationship between social prison's elements and social prisoner phenomenon in Pakistan. So, it can be asserted with some certainty that, individuals of the $21^{\text {st }}$ century do live in a kind of prison called "Social Prison" hence; they can be termed as "Social Prisoners".
\end{abstract}

\section{Keywords}

Material Acquisitions (M.A), Social Status Quo (S.S.Q), Social Prison, Social Prisoner, Relationship

\section{Introduction}

It is a historical perspective that societies do follow multiple ideologies in order to comprehend the multiple realities existing in their surroundings and also to create values and norms based upon those, individual actions can be perceived and guided. The idea of consumerist society can be dated back to the emergence 
of capitalist model back in the late $18^{\text {th }}$ century, but, that ideology has erupted intensely with the help of technology and stable political world order after the second wave of industrialization [1]. Stearns (2001) hence argued that consumerism is an abstract construct that allows the humans to equate personal happiness with buying more material goods and accessories with or without need because, it is just not about buying but creating social status and self-identity through it. However, the creation of self-identity and the process of internalization are not new as the humans used to form their identity based on gender, occupation and location as well but, the divisions were clearly defined and its boundaries were well encircled in the past but, that phenomenon has become the trend of past not the present as the concept of neo-tribalism has emerged [2]. It was Hetherington in 1989, who gave this idea of identity formation not based on any fixed construct (e.g. occupation, gender) but the concept of fluidity and permeability. Hence, he called them "communities of feeling" [3]. Therefore, in today's society, the self is attached with the products and commodities and it is not the self that determines the value of those, but it is the opposite, the products or commodities defining and determining the self; hence Todd (2012) correctly mentioned the transformation of individualism in the past with the emergence of small community groups in the present with the expression "who am I" replaced with "who are we" or "with whom do I belong". He further argued that, consumption has become the way for the consumer or the member of the society to communicate with the society at large and find its fit within the society [4]. Conversely, Cova (1997) defined tribe as "networks of heterogeneous people, who are linked by a shared passion or emotion; a tribe is capable of collective action, its members are not simple consumers, they are also advocates" [5]. In the similar line of thought Sollars (1989) mentioned the neo-tribes and the importance of traditions in those tribes as similar to the older tribes but, the form and process have been changed in order to match with the modern society [6]. In neo-tribes as well, the members do detach themselves from other groups based on their choice of products, their location of residence and even their choice of food. Those are the traditions bind the members of one group together (e.g. Vegetarian, Minimalist). However, it was Cova (1997) who was greatly influenced by work of Mafessoli and his theory of break-up of mass culture that motivates him to study neo-tribes and eventually successfully, he divided the concept of neo-tribes into two broader types: Temporal and Spatial. Temporal tribes are formed based on their immediate objective/s, they usually appear, become bigger, reach its threshold and then dissolve because, they are fragmented and timeless, those can be the examples of social media campaigns and other such activities [5]. Spatial are those who can be observed at public places by performing rituals like environmental friendly groups and others. Those tribes do stay longer because, the objective seems to be bigger in perspective and achievement of it is no longer possible without the constant reinforcement of rituals [7]. However, Mafessoli (1996) criticized on the idea of these tribes as he argued that, point of reference where they understand a particular phenomenon is a refer- 
ence point of a certain group not the whole society so, they miss the bigger picture perspective [8]. Hence, this study has observed the phenomenon of social prisoner as the individuals are living a life similar to a prison; however, the change is only the type of prison and location of it, without changing the underlying and influential ideology of consumerism in one way or another. It is also a reality that human beings live in two different worlds, the world that is physical and that world can be seen, touched and observed and the world that is built into the minds of each and every individual and the interaction of both creates the situation that can be regarded as enclave or prison.

Social prisoner means a person or an individual living a life inside a psychological prison (squared four walled space), the walls in the prison are being defined as continuous craving for acquisition (money, property, etc.), maintaining social status quo (I should keep a car because my colleague has the one), social envy (neighbours/ relatives are more wealthier) and finally following social rituals (getting higher education, have to marry, etc.). Hence, the freedom and free will of living your life with your own choice have been curtailed by materialistic values, consumerism, fake associations, endless competition, thereby, it could be presumed somehow that in the $21^{\text {st }}$ century, the individuals are living a life that can be regarded as a life of a "Social Prisoner".

However, the concept of prison is not new as it is old as when humans had the idea of what is being accepted as normal and what is not (e.g. ancient Greeks and social contract). Although, the punishment definition was given earlier by Newman (1978) as "It is a pain or other unpleasant consequence that results from an offense against a rule and that is administered by others, who represent legal authority, to the offender who broke the rule" [9] [10]. Therefore, it must involve the infliction of pain or discomfort. In the similar line of thought, it is also a confinement of an individual or individuals in a cell (four-walled space) [11]. But, this research has not focused on the real prison and putting those people behind bars who break the laws made by the individual societies but, on the psychological prison, that exists in its abstract form but, do influence on understating and managing the day to day actions of individuals and create realities in respective societies, those may not be possible to manifest without its abstract foundation, thereby producing an environment as similar to social or cultural prison. Thus, this research has chosen prison as a metaphor of an imaginary prison that consists of four walls (Material Acquisitions, Social Status Quo, Social Envy and Social Rituals) and that subsequently constitute a social or cultural prison in which individuals live with or without knowing about it.

\section{Material Acquisitions (MA)}

Belk (1985) has elaborated materialism as the "importance a person attaches to worldly possessions" [12]. However, Scott (2009) mentioned materialism as an individual's preference towards material objects over spiritual values; hence, a negative meaning is ascribed to it [13]. The negative idea is reinforced by Twitchell (1999) by saying that "it is wasteful, it is devoid of otherworldly concerns, it 
lives for today and celebrates the body, and it overindulges and spoils the young with impossible promises" [14]. In fact, at a cultural level, the widespread prevalence of materialism has been labeled as affluenza [15]. O'Neill (1997) suggested this explicitly as "the collective addictions, character flaws, psychological wounds, neuroses, and behavioral disorders caused or greatly exacerbated by the presence of or desire for excess material objects or money or wealth" [16]. Kasser (2002) added into the literature of materialism by pointing out the physiological and psychological needs of the humans. He mentioned that, whether it is intrinsic or extrinsic needs, in today's world, human try to satisfy both needs through the means of wealth. However, he suggested that psychological needs can't be fulfilled through the material possessions of objects [17]. Similarly, Arndt et al., (2004) elaborated that, intrinsic needs are not possible to get only through the possession of material objects [18]. However, pursuit of material objects is a universal human goal and the idea is to advertise one's wealth status and resourcefulness and increase competency [19] [20]. Although, the psychological well-being is undermined as an outcome of conflict between personal and societal values. It has been mentioned in several studies (Asian or Western contexts), that materialism is inversely related to life satisfaction [21]. Hence, the more the individuals need, the more dissatisfied they become because, the idea of "objectification equals to happiness" possesses inherent fallacy of dissatisfaction. Therefore, the constant search of life satisfaction and well-being through objectification beyond certain level is an unfulfilled dream of the $21^{\text {st }}$ century individuals. Hence, the individuals are living a life of a social prisoner because, they are keen to get rid of their phycological pain and suffering through acquisition of material objects.

\section{Social Status Quo (S.S.Q):}

Social status quo concept is also not new but, its boundaries and the framework within which its actors act were will defined and articulated. However, with the emergence of mass production and vibrant consumerism and rapid capitalism, it is hard to define and elaborate it but, it can be associated with lifestyle and other demographic factors. Hence, Weber (1946) distinguished between class and status and that is why fisher (1987) mentioned that "Status symbols essentially embody the conjunction of Weber's class and status dimensions. An individual can employ consumer goods as status symbols and in so doing attempt to claim a particular social standing or to attribute social significance to his behavior" [22] [23]. However, when connecting it with lifestyle, Kesic \& Rajh-Piri (2003) mentioned lifestyle as the way through which individuals decide to live and spend their time and money [24]. Lindquist and Sirgy (2003) have emphasized that lifestyle can be considered as a collection of individual characteristics and behaviors and those can also be influenced through socio-cultural variables such as age, gender, ethnicity, social group and religion [25]. Although, the consumption in its primary focus is beneficial because, it helps in fulfilling the basic needs and demands of the individual but, it has changed nowadays to "Compensatory consumption" that ascribe class and sta- 
tus. For instance, a family with limited financial resources can easily calculate that high-priced luxuries are beyond their means; however, that similar family can use alternative resources in order to get involved in various forms of social or cultural consumption which ultimately provides the similar form of satisfaction and status and hence, money can be spent in a manner intended to compensate for limited access to highly restricted social circles [23]. That is why, social status in a "consumer society" can be gauged by its use of time and money for owning things because, it is their belief that, it can ultimately lead towards increasing social value and getting everlasting happiness-the supreme goal in one's life, however, it is an ever-perpetuated fallacy in itself. Hence, the individual lifestyles and identities have been associated with consumption activities; that is why consumerism is based on accepting consumption "as the way to self-development, self-realization, and self-fulfillment" [26]. Hence, this research emphasizes that, individuals live in a social prison because of the idea that is constantly rein forced by the society in one way or another that "Either you are from us or not" puts the individuals in perpetual state of distress, anxiety and depression that may or may not lead to neurosis, that is a common disease found in prisoners.

\section{Social Envy (S.E):}

Envy can be regarded as a negative feeling for someone who has something that is being dreamed of by another individual [27] [28]. Alternatively, envy is an internal resentment against individual or individual (e.g. lower middle income for middle income or middle income for upper class). Envy usually is usually based upon the objective qualities like wealth, status, power, fame, success, talent, good health, good grades, good looks, and popularity. Envy is not absolute in nature but relative in a sense that, it can provide the malicious pleasure (e.g. someone losing their wealth, their power or social status) [29]. Social envy is a phenomenon that occurs when individuals living in a particular society start comparing their present financial, social or even educational position with someone having higher attributes than them, Kant (1997) called it as an "Upward comparison". Hence, he mentioned that "Envy is thus not the pain that arises when others do well, but rather it is the pain that arises when others do better than oneself" [30]. However, it was Clanton (2006) through his book on Jealousy and Envy highlighted the events that can infuse the feeling of envy in human individual like he mentioned that, "Your best friend wins a coveted scholarship or award or your neighbor wins the lottery. A co-worker gets a raise or a promotion, but you do not. Another woman becomes pregnant but, when you cannot. The star of the team gets a huge salary rise and most of the press attention but, you don't. In each case, if you could be 100 percent happy for the other with no qualifications or second thoughts, you would be without envy" but that is most of the times impossible [31]. Clanton (2006) further mentioned that "if in any case, to whatever degree you find yourself, even for a moment, thinking the other does not deserve the good fortune or wishing that the other would lose his or her advantage or otherwise suffers that is a measurement of your be- 
ing envious" [31]. Hence, that envy leads the $21^{\text {st }}$ individuals in the game of constant comparison and that comparison puts them in the merry-go-round circle that has no end until someone jumps off and loses his/her body permanently. Therefore, the individuals living a life of a social prisoner because, they always repeat the same activities and feel in the similar fashion without doing any kind of introspection that those feeling and actions are beneficial for them or not or even for the sub-group they belong or for the larger community in which they are situated.

Social Rituals (S.R):

Human society has evolved from the age of hunter gathers to the age of human civilization and in the process, the culture has played a key role. The culture can be a collective form of rituals, norms and trends [32]. Social Rituals can be considered as any permanent or stereotyped practice, behavioral pattern, that don't have any obvious and clear instrumental objective except gestural communication or symbolization [33]. Ritual can be denoted to any activity with the high degree of formality and non-instrumental purpose [34]. Hence, rituals are playing a key role in both ancient and modern consumption patterns, however, it is well articulated by food historians, who have accumulated the infinite number of rituals that can be exemplified as the slaughter, preparation, and consumption of food and beverages [35]. Similarly, Rossano (2012) mentioned the birthday ritual as taking the typical act of eating and ceremonializing it with ritualized actions [36]. Consumption has become a social ritual through clothing and food in which members of same group or neo-tribe apply to similar standards and guidelines as Sadian (2017) highlighted that, consumers are not buying the clothes in order to fulfill their basic needs but, in order to attach themselves with certain social group. Hence, clothing has been symbolized as new gesture for social stratification [37]. The similar kind of reasoning is mentioned in social identity theory by Tajfel and Turner (1985) in which they decomposed the person's identity into two forms personal and social [38]. Hence, depersonalization is used in social psychology to describe an individual's shift in focus from their personal identity to their social identity [39]. Otnes and Lowrey (2004) have discussed that, the customer rituals of buying products are not intended to just using those products or for the instrumental purpose of it but to create value from those products by converting them into memorable moments that can be shared within their community [40]. However, the human performing rituals phenomenon is not new but, the consumption rituals determining the social positioning depending on different locality, social status and occupation is something that needs to be investigated. In this regard, Van Gennep (1960) proposed three stages and based upon those, individuals transform from their present social identity to the new identity or the separation between profane and sacred [41]. Turner (1969) however, elaborated this idea from the sociological point of view by arguing that, individuals changing from one state into another, usually follow the three stages: Separation, Intermediate and Incorporation. In the separation stage, individuals normally free themselves from their current so- 
cial structure by not following the rituals holding that social structure like not dressing in a way they dressed before. Furthermore, when they breakup with their existing social structure, they usually move to a new social structure and follow new rituals like taking food on their weekends in their favorite restaurant is an urban ritual that can't be found in rural settings [42]. Gradually and slowly, they incorporate themselves into new social settings like one neo-tribe of upper class moves into the neo-tribe of environmentalist or minimalist or rural individuals to urban settings. Although, the consumption ritual remains the same but just in a different format hence, the social prison wall of social ritual also remains the same, however, the wall merely changes its characteristics.

\section{Problem Statement:}

It has been seen that consumerism has emerged as the only potent and vibrant ideology that spread not in any single geographical area but in the whole world. Thus, Miller (2007) defined consumerism as it is a theory that motivates towards greater consumption of goods as it is economically beneficial, but it also describes the attachment to materialistic values or possessions [43]. Consumption has not only nailed its feet on the human's physical needs and desires but, it has also changed the way one can look into its own one's self. It has become the underpinning foundation based upon which social class, status and lifestyle are determined. Hence, Consumption has become the means of identity creation [44]. Therefore, contemporary thinking no longer perceive identity as fixed and unitary, but as malleable and multiple, and in many respects as the product of a self-constructed narrative with varying relationships to multiple in- and out-groups, with behavioral tendencies towards intra-group solidarity and inter-group competition or distinction [45]. As it has been argued in social identity theory that, identity can be considered as a process of negotiation in which different social roles are learned in relations with others and hence individuals are engaged in identity-creating interactions every day [44]. Hence, humans living in today's era are living a life of a neurotic kind because, they live in constant quest for material acquisitions, maintaining social status quo, pervasive social envy and following compulsory social rituals, they all form a kind of imaginary social prison in which humans live with or without its conscious awareness. Hence, it is quite important to explore and understand the impact of that phenomenon on individual's physical and psychological self and to create understating of individual's thinking pattern and actions.

\section{Hypotheses:}

$\mathrm{H1}=$ There is a significant relationship between Material Acquisitions and Social Prisoner phenomenon in Pakistan

$\mathrm{H} 2$ = There is a significant relationship between Social Status Quo and Social Prisoner phenomenon in Pakistan

H3 = There is a significant relationship between Social Envy and Social Prisoner phenomenon in Pakistan

H4 = There is a significant relationship between Social Rituals and Social Prisoner phenomenon in Pakistan 
$\mathrm{H} 5=$ There is a significant relationship between cumulative elements of Social Prison and Social Prisoner phenomenon in Pakistan

\section{Conceptual Framework:}

The study is guided by Mafessoli (1996) break-up of mass culture theory and Cova (1997) who was greatly influenced by Mafessoli, studied neo-tribes extensively and eventually successfully divided the concept of neo-tribes into two broader types: Temporal and Spatial. The study was also guided by Weber (1946) class and status distinction theory and Fisher (1987) understanding of it as "Status symbols essentially embody the conjunction of Weber's class and status dimensions. An individual can employ consumer goods as status symbols and in doing so he/she attempts to claim a particular social standing or to attribute social significance to his behavior". Hence, this study has proposed four imaginary walls: Material Acquisitions, Social Status Quo, Social Envy and Social Rituals. Those all cumulatively form a social prison in which individuals live in the $21^{\text {st }}$ century and hence, the difference between reality and "what is actually real" is slowly and gradually vanishing (Figure 1 ).

\section{Research Methodology}

This research is based upon the philosophy of post-positivism as post-positivism has defined as it is important to understand positivism and then post-positivism. The positivist approach is closely related the "scientific approach", that proclaim that there is only one single objective "truth" with verifiable patterns those can be predicted with certainty. Positivism, however, believes on "truth" which can be attained through methodical, rigorous and careful observation and is testified through repeatable methodologies. However, post-positivist is based upon the idea of fallibilism that implies that, absolute knowledge is impossible. It further suggests that, there is no single truth and the truth can be changed based on new findings and facts so, it is changeable, not fixed in nature [46]. Hence, this research is based on post-positivism because; the phenomenon can be revisited with new data and insights. It is basically a quantitative research and cross-sectional in nature as, the data is collected only at single point in time from respondents. The respondents have been chosen by criteria of their minimum age, qualification and whether they are currently working somewhere. The respondents are only those individuals working formally in any kind of field ranging from education to banking sector in Pakistan. The respondents are as diverse

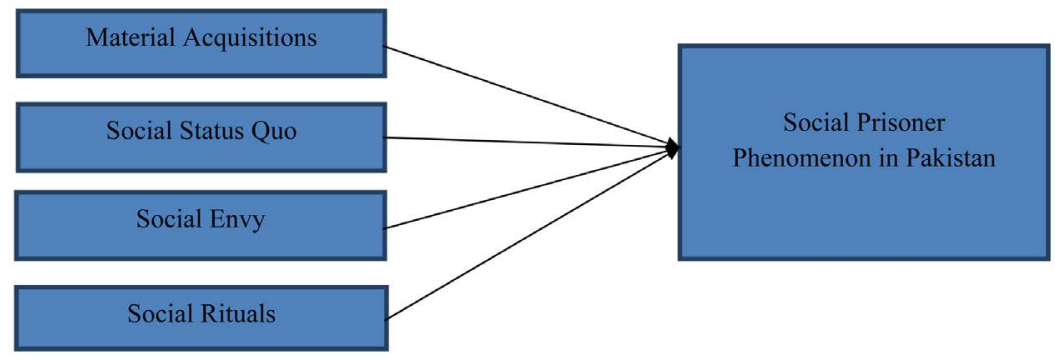

Figure 1. The conceptual framework of the study. 
as possible in their socio-economic background and locality. This research is not the research that has any specific population target except the population of the country that is quite big to cover anyway, hence, the respondents have been chosen based on their consent for participation in the study. That is why, the sample size is only $170+$ respondents and the convenience sampling technique is used because of easy access to respondents and financial as well as time constraints. The respondents have also been chosen based on their academic background in English and whether they can understand the language of the questionnaire or not because, English is not the widely spoken language in the country. However, the research instrument reliability has been found and acceptable level of SPSS Cronbach's alpha value has been obtained.

\section{Results and Analysis}

This section is divided into two parts: Descriptive and Inferential analysis.

\subsection{Descriptive Analysis}

Descriptive data analysis is the technique used to summarize the data and find patters in the sample that can determine the inclination of respondents towards a particular phenomenon in one way or another. It is used to describe a phenomena that how the respondents think about the particular concept or construct. It is an attempt to examine the situations in order to describe the norm [47]. It describes what exists and tries to pave the ground for finding new facts. It also include gathering of data that is related to products, people, individuals, events and situations and then organize them into tabular form in order to, depict and describe the outcome [48]. Hence, this research is going to find out the trend of the data through descriptive analysis and whether the respondents are more or less agreed or disagreed with the concept of social prisoner as a whole.

\section{Age of the Respondents:}

Table 1. Describing the age of the respondents.

\begin{tabular}{cccccc}
\hline & Frequency & Percent & $\begin{array}{c}\text { Valid } \\
\text { Percent }\end{array}$ & $\begin{array}{c}\text { Cumulative } \\
\text { Percent }\end{array}$ \\
\hline $22-26$ & 59 & 33.7 & 33.7 & 33.7 \\
& $26-30$ & 50 & 28.6 & 28.6 & 62.3 \\
& $30-34$ & 32 & 18.3 & 18.3 & 80.6 \\
& $34-38$ & 17 & 9.7 & 9.7 & 90.3 \\
& $38-42$ & 17 & 9.7 & 9.7 & 100.0 \\
& Total & 175 & 100.0 & 100.0 & \\
\hline
\end{tabular}

The above Table 1 shows that, more than $60 \%$ of the respondents were under the age of 30 .

Qualification of the Respondents: 
Table 2. Describing the qualification of the respondents.

\begin{tabular}{cccccc}
\hline & & Frequency & Percent & $\begin{array}{c}\text { Valid } \\
\text { Percent }\end{array}$ & $\begin{array}{c}\text { Cumulative } \\
\text { Percent }\end{array}$ \\
\hline \multirow{3}{*}{ Valid } & Bachelor's Degree (Any subject) & 76 & 43.4 & 43.4 & 43.4 \\
& Master's Degree (Any subject) & 82 & 46.9 & 46.9 & 90.3 \\
& PhD Degree (Any subject) & 17 & 9.7 & 9.7 & 100.0 \\
& Total & 175 & 100.0 & 100.0 & \\
\hline
\end{tabular}

The above data (Table 2) shows that, almost the equal number of respondents participated in the study had bachelors or masters' degree.

How much are you satisfied with your current status of living?

Table 3. Describing the statistics of the third question of the research.

\begin{tabular}{cccccc}
\hline & & Frequency & Percent & $\begin{array}{c}\text { Valid } \\
\text { Percent }\end{array}$ & $\begin{array}{c}\text { Cumulative } \\
\text { Percent }\end{array}$ \\
\hline Quite satisfied & 77 & 44.0 & 44.0 & 44.0 \\
Just satisfied & 69 & 39.4 & 39.4 & 83.4 \\
Valid & I don't know & 10 & 5.7 & 5.7 & 89.1 \\
& Not satisfied & 12 & 6.9 & 6.9 & 96.0 \\
& Not satisfied at all & 7 & 4.0 & 4.0 & 100.0 \\
Total & 175 & 100.0 & 100.0 & \\
\hline
\end{tabular}

The above data (Table 3) exhibits that, more than $80 \%$ of the respondents were satisfied with their current status of living, while only $10 \%$ of them were dissatisfied with their current status of living.

How often do you feel that your life is controlled by others (family/friends/boss/peers/community members)?

Table 4. Describing the statistics of the fourth question of the research.

\begin{tabular}{|c|c|c|c|c|c|}
\hline & & Frequency & Percent & $\begin{array}{c}\text { Valid } \\
\text { Percent }\end{array}$ & $\begin{array}{c}\text { Cumulative } \\
\text { Percent }\end{array}$ \\
\hline \multirow{6}{*}{ Valid } & Very often (5 times in a week) & 41 & 23.4 & 23.4 & 23.4 \\
\hline & Often ( 3 times in a week) & 40 & 22.9 & 22.9 & 46.3 \\
\hline & Once in a while (once every week) & 40 & 22.9 & 22.9 & 69.1 \\
\hline & Not frequently & 34 & 19.4 & 19.4 & 88.6 \\
\hline & Not at all & 20 & 11.4 & 11.4 & 100.0 \\
\hline & Total & 175 & 100.0 & 100.0 & \\
\hline
\end{tabular}

The above table (Table 4) shows that, almost $70 \%$ of the respondents feel that, their life is controlled by others whether family, friends or peers at least once. However, slightly more than $10 \%$ were disagreed with the notion. 
How often cultural restrictions push you to make concessions in your life (leaving your dream, leaving people you like to stick to, getting along with people you don't like)?

Table 5. Describing the statistics of the fifth question of the research.

\begin{tabular}{|c|c|c|c|c|c|}
\hline & & Frequency & Percent & $\begin{array}{c}\text { Valid } \\
\text { Percent }\end{array}$ & $\begin{array}{c}\text { Cumulative } \\
\text { Percent }\end{array}$ \\
\hline \multirow{6}{*}{ Valid } & Very often (5 times in a week) & 31 & 17.7 & 17.7 & 17.7 \\
\hline & Often ( 3 times in a week) & 35 & 20.0 & 20.0 & 37.7 \\
\hline & Once in a while (once every week) & 44 & 25.1 & 25.1 & 62.9 \\
\hline & Not frequently & 40 & 22.9 & 22.9 & 85.7 \\
\hline & Not at all & 25 & 14.3 & 14.3 & 100.0 \\
\hline & Total & 175 & 100.0 & 100.0 & \\
\hline
\end{tabular}

The above data (Table 5) shows that, more than $60 \%$ of the respondents agreed on the notion that, cultural restrictions do push them to make concessions in their life at least once, whether in the case of leaving their dream or getting along with people they don't like. However, more than $10 \%$ were disagreed with the idea.

How often do you think that you are trapped in a rat race cycle?

Table 6. Describing the statistics of the sixth question of the research.

\begin{tabular}{|c|c|c|c|c|c|}
\hline & & Frequency & Percent & $\begin{array}{c}\text { Valid } \\
\text { Percent }\end{array}$ & $\begin{array}{c}\text { Cumulative } \\
\text { Percent }\end{array}$ \\
\hline \multirow{6}{*}{ Valid } & Very often (5 times in a week) & 55 & 31.4 & 31.4 & 31.4 \\
\hline & Often ( 3 times in a week) & 34 & 19.4 & 19.4 & 50.9 \\
\hline & Once in a while (once every week) & 38 & 21.7 & 21.7 & 72.6 \\
\hline & Not frequently & 27 & 15.4 & 15.4 & 88.0 \\
\hline & Not at all & 21 & 12.0 & 12.0 & 100.0 \\
\hline & Total & 175 & 100.0 & 100.0 & \\
\hline
\end{tabular}

The above table (Table 6) illustrate that, more than $70 \%$ of the respondents agreed on the idea that, they think that, they are trapped in a rat race cycle at least once in their life means, they understand that, first they find job, then earn money and afterwards, that leads to a social status quo and eventually they become so involved in that cycle of work, money and social status quo that, they are trapped in a rat race cycle. However, slightly more than $10 \%$ were disagreed with the notion.

How often do you feel that you have sacrificed your most important goal/goals in order to satisfy the social norms/trends in the culture (earning a lot of money/getting married/buying property/supporting your family/etc.)? 
Table 7. Describing the statistics of the seventh question of the research.

\begin{tabular}{|c|c|c|c|c|c|}
\hline & & Frequency & Percent & $\begin{array}{l}\text { Valid } \\
\text { Percent }\end{array}$ & $\begin{array}{c}\text { Cumulative } \\
\text { Percent }\end{array}$ \\
\hline \multirow{6}{*}{ Valid } & Very often (5 times in a week) & 44 & 25.1 & 25.1 & 25.1 \\
\hline & Often ( 3 times in a week) & 37 & 21.1 & 21.1 & 46.3 \\
\hline & Once in a while (once every week) & 29 & 16.6 & 16.6 & 62.9 \\
\hline & Not frequently & 42 & 24.0 & 24.0 & 86.9 \\
\hline & Not at all & 23 & 13.1 & 13.1 & 100.0 \\
\hline & Total & 175 & 100.0 & 100.0 & \\
\hline
\end{tabular}

The above Table 7 illustrate that, more than $60 \%$ of the respondents agreed on the perception of the researcher that, at least once, they have sacrificed their most important goal/goals in order to satisfy the social norms/trends in the culture whether in the form of earning a lot of money/getting married/buying property or even supporting their family. However, almost $14 \%$ were disagreed with the idea as well.

How often do you feel sad or depressed or unmotivated because of not living your life in a way, you wanted to live?

Table 8. Describing the statistics of the eighth question of the research.

\begin{tabular}{cccccc}
\hline & & Frequency & Percent & $\begin{array}{c}\text { Valid } \\
\text { Percent }\end{array}$ & $\begin{array}{c}\text { Cumulative } \\
\text { Percent }\end{array}$ \\
\hline Very often (5 times in a week) & 33 & 18.9 & 18.9 & 18.9 \\
Often (3 times in a week) & 49 & 28.0 & 28.0 & 46.9 \\
Valid & Once in a while (once every week) & 44 & 25.1 & 25.1 & 72.0 \\
& Not frequently & 25 & 14.3 & 14.3 & 86.3 \\
Not at all & Total & 175 & 100.0 & 100.0 & 100.0 \\
\hline
\end{tabular}

The above Table 8 shows that, more than $70 \%$ of the respondents agreed on the idea of the researcher that, at least once, they do feel sad or depressed or unmotivated because of not living their life in a way, they wanted to live eventually. However, more than $10 \%$ were disagreed with the idea as well.

How often do you feel that you are trapped in a social or cultural prison?

Table 9. Describing the statistics of the ninth question of the research.

\begin{tabular}{cccccc}
\hline & & Frequency & Percent & $\begin{array}{c}\text { Valid } \\
\text { Percent }\end{array}$ & $\begin{array}{c}\text { Cumulative } \\
\text { Percent }\end{array}$ \\
\hline \multirow{2}{*}{ Very often (5 times in a week) } & 30 & 17.1 & 17.1 & 17.1 \\
Valid & Often (3 times in a week) & 28 & 16.0 & 16.0 & 33.1 \\
& Once in a while (once every week) & 45 & 25.7 & 25.7 & 58.9 \\
$\quad$ Not frequently & 49 & 28.0 & 28.0 & 86.9 \\
Not at all & 23 & 13.1 & 13.1 & 100.0 \\
Total & 175 & 100.0 & 100.0 & \\
\hline
\end{tabular}


The above Table 9 elucidates that, almost $60 \%$ of the respondents agreed on the perception of the researcher that, at least once, they felt that, they are living in a cultural or social prison. However, $28 \%$ of them felt that, they are living in a prison but not frequently and only $13 \%$ of them argued that, they don't think that, they are living in any cultural or social prison.

\subsection{Inferential Analysis}

It is the statistical technique that is used by the researcher to test the research hypotheses and then afterwards, drawing inferences from the findings of a study [49]. However, these statistical techniques can be divided into two major types, nonparametric tests and the parametric tests. The nonparametric tests can include the chi-square test and the Kolmogorov-Sminov test while the parametric tests include the t-test, analysis of variance and Pearson Product Moment Correlation Coefficient [50]. Hence, the research has used Pearson and Spearman correlation coefficient tests in order to find out the relationship between each independent and dependent variables.

\section{Hypothesis Testing:}

\section{Hypothesis 1:}

$\mathrm{H} 1$ = There is a significant relationship between Material Acquisitions and Social Prisoner phenomenon in Pakistan

Table 10. H1 Pearson's correlation.

\begin{tabular}{cccc}
\hline & & S.S.Q & S.P \\
\hline S.S.Q & Pearson Correlation & 1 & $0.330^{* *}$ \\
& Sig. (2-tailed) & & 0.000 \\
& $\mathrm{~N}$ & 175 & 175 \\
& Pearson Correlation & $0.330^{* *}$ & 1 \\
& Sig. (2-tailed) & 0.000 & 175 \\
\hline
\end{tabular}

${ }^{* *}$ Correlation is significant at the 0.01 level (2-tailed).

Table 11. H1 spearman's correlation.

\begin{tabular}{|c|c|c|c|c|}
\hline & & & S.S.Q & S.P \\
\hline \multirow{6}{*}{ Spearman's rho } & \multirow{3}{*}{ S.S.Q } & Correlation Coefficient & 1.000 & $0.338^{* *}$ \\
\hline & & Sig. (2-tailed) & & 0.000 \\
\hline & & $\mathrm{N}$ & 175 & 175 \\
\hline & \multirow{3}{*}{ S.P } & Correlation Coefficient & $0.338^{\star *}$ & 1.000 \\
\hline & & Sig. (2-tailed) & 0.000 & \\
\hline & & $\mathrm{N}$ & 175 & 175 \\
\hline
\end{tabular}

${ }^{* *}$ Correlation is significant at the 0.01 level (2-tailed). 
The above both (Table 10 \& Table 11) tests show that, there is a significant relationship between Material Acquisitions and Social Prisoner phenomenon in Pakistan because the $\mathrm{p}$ value is lesser than 0.05 and therefore, the first hypothesis is accepted. However, the strength of relationship between the two variables is weak considering the fact that, the sample size was quite low. But it can be narrated with some certainty that material acquisitions play their role in the formation of social prison.

Hypothesis 2:

$\mathrm{H} 2=$ There is a significant relationship between Social Status Quo and Social Prisoner phenomenon in Pakistan

Table 12. H2 Pearson's correlation.

\begin{tabular}{cccc}
\hline & & M.A & S.P \\
\hline M.A & Pearson Correlation & 1 & $0.174^{\star}$ \\
& Sig. (2-tailed) & & 0.022 \\
& N & 175 & 175 \\
S.P & Pearson Correlation & $0.174^{*}$ & 1 \\
& Sig. (2-tailed) & 0.022 & 175 \\
\hline
\end{tabular}

${ }^{*}$ Correlation is significant at the 0.05 level (2-tailed).

Table 13. H2 spearman's correlation.

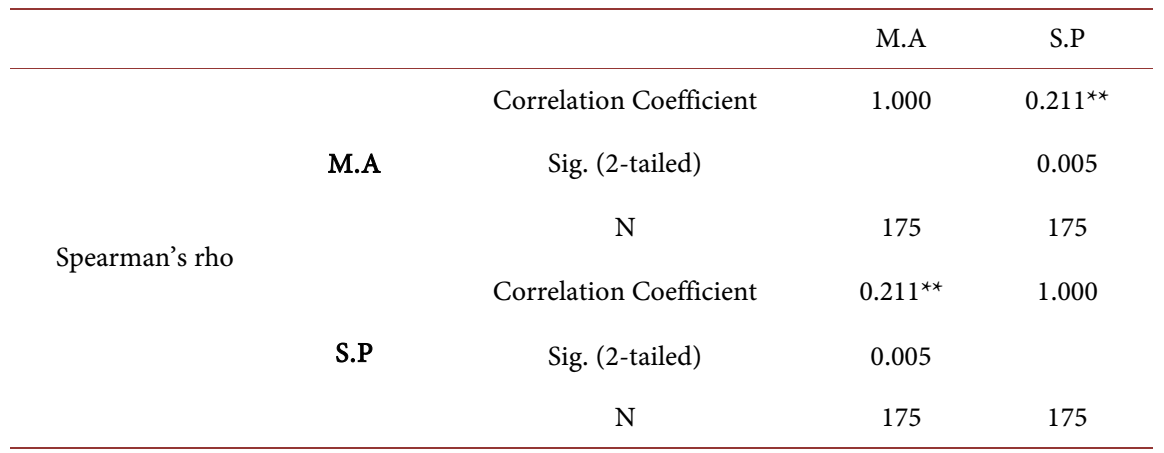

${ }^{* *}$ Correlation is significant at the 0.01 level (2-tailed).

The Pearson and Spearman results (Table 12 \& Table 13) can exhibit that, there is a significant relationship between Social Status Quo and Social Prisoner phenomenon in Pakistan because the $\mathrm{p}$ value is lesser than 0.05 and therefore, the second hypothesis is hence accepted. However, the strength of relationship between the two variables seems to be weak because of the fact that, the sample size was quite low. But it can be inferred from the results that pressure to maintain social status quo do contribute in the formation of social prison.

\section{Hypothesis 3:}

H3 = There is a significant relationship between Social Envy and Social Prisoner phenomenon in Pakistan 
Table 14. H3 Pearson's correlation.

\begin{tabular}{cccc}
\hline & & S.E & S.P \\
\hline S.E & Pearson Correlation & 1 & $0.278^{* *}$ \\
& Sig. (2-tailed) & & 0.000 \\
& $\mathrm{~N}$ & 175 & 175 \\
& Pearson Correlation & $0.278^{* *}$ & 1 \\
S.P & Sig. (2-tailed) & 0.000 & 175 \\
\hline
\end{tabular}

${ }^{* *}$ Correlation is significant at the 0.01 level (2-tailed).

Table 15. H3 spearman's correlation.

\begin{tabular}{lcccc}
\hline & & S.E & S.P \\
\hline & & Correlation Coefficient & 1.000 & $0.280^{* *}$ \\
& S.E & Sig. (2-tailed) & & 0.000 \\
Spearman's rho & N & 175 & 175 \\
& S.P & Correlation Coefficient & $0.280^{* *}$ & 1.000 \\
& & Sig. (2-tailed) & 0.000 & \\
& & $\mathrm{~N}$ & 175 & 175 \\
\hline
\end{tabular}

${ }^{*}$ Correlation is significant at the 0.01 level (2-tailed).

The both correlational tests (Table $14 \&$ Table 15) show that, there is a significant relationship between Social Envy and Social Prisoner phenomenon in Pakistan because the $\mathrm{p}$ value is found to be lesser than 0.05 and therefore, the third hypothesis of the study is also accepted. However, the strength of relationship between two variables is discovered to be weak considering the fact that, the sample size was quite low. But it can be narrated with some certainty that Social envy has a role to play in the formation of social prison.

\section{Hypothesis 4:}

$\mathrm{H} 4=$ There is a significant relationship between Social Rituals and Social Prisoner phenomenon in Pakistan

Table 16. H4 Pearson's correlation.

\begin{tabular}{cccc}
\hline & & S.R & S.P \\
\hline S.R & Pearson Correlation & 1 & $0.335^{\star *}$ \\
& Sig. (2-tailed) & & 0.000 \\
& $\mathrm{~N}$ & 175 & 175 \\
S.P & Pearson Correlation & $0.335^{\star *}$ & 1 \\
& Sig. (2-tailed) & 0.000 & 175 \\
\hline
\end{tabular}

${ }^{* *}$ Correlation is significant at the 0.01 level (2-tailed). 
Table 17. H4 spearman's correlation.

\begin{tabular}{|c|c|c|c|c|}
\hline & & & S.R & S.P \\
\hline \multirow{6}{*}{ Spearman's rho } & \multirow{3}{*}{ S.R } & Correlation Coefficient & 1.000 & $0.374^{\star *}$ \\
\hline & & Sig. (2-tailed) & & 0.000 \\
\hline & & $\mathrm{N}$ & 175 & 175 \\
\hline & \multirow{3}{*}{ S.P } & Correlation Coefficient & $0.374^{\star \star}$ & 1.000 \\
\hline & & Sig. (2-tailed) & 0.000 & \\
\hline & & $\mathrm{N}$ & 175 & 175 \\
\hline
\end{tabular}

${ }^{* *}$ Correlation is significant at the 0.01 level (2-tailed).

The above both tests (Table $16 \&$ Table 17) show that, there is a significant relationship between Social Rituals and Social Prisoner phenomenon in Pakistan because the $\mathrm{p}$ value is lesser than 0.05 and hence, the fourth and second last hypothesis is also accepted. However, the strength of relationship between the two variables can be considered weak. However, the above results imply that social rituals are contributing into the formation of social prison.

Hypothesis 5:

$\mathrm{H} 5=$ There is a significant relationship between cumulative elements of Social Prison and Social Prisoner phenomenon in Pakistan

Table 18. H5 Pearson's correlation.

\begin{tabular}{|c|c|c|c|}
\hline & & Social. Prison & S.P \\
\hline & Pearson Correlation & 1 & $0.383^{\star *}$ \\
\hline \multirow[t]{3}{*}{ Social. Prison } & Sig. (2-tailed) & & 0.000 \\
\hline & $\mathrm{N}$ & 175 & 175 \\
\hline & Pearson Correlation & $0.383^{\star \star}$ & 1 \\
\hline \multirow[t]{2}{*}{ S.P } & Sig. (2-tailed) & 0.000 & \\
\hline & $\mathrm{N}$ & 175 & 175 \\
\hline
\end{tabular}

${ }^{*}$ Correlation is significant at the 0.01 level (2-tailed).

Table 19. H5 Spearman's correlation.

\begin{tabular}{lcccc}
\hline & & & Social. Prison & S.P \\
\hline & Social. & Correlation Coefficient & 1.000 & $0.419^{* *}$ \\
& Prison & Sig. (2-tailed) & & 0.000 \\
Spearman's rho & & $\mathrm{N}$ & 175 & 175 \\
& S.P & Correlation Coefficient & $0.419^{* *}$ & 1.000 \\
& & Sig. (2-tailed) & 0.000 & \\
& & $\mathrm{~N}$ & 175 & 175 \\
\hline
\end{tabular}

${ }^{* *}$ Correlation is significant at the 0.01 level (2-tailed). 
The above both tests (Table 18 \& Table 19) show that, there is a significant relationship between each of the elements of social prison as a whole (Material Acquisitions, Social Status Quo, Social Envy and Social Rituals) and social prisoner phenomenon in Pakistan. However, the strength of the relationship was unearthed to be moderate in both tests as it was found to be near to $40 \%$ in both tests.

\section{Discussion}

This study was conducted in order to understand a concept of a psychological prison and how the four distinct elements of that prison or the walls of that prison (Material Acquisitions, Social Status Quo, Social Envy and Social Rituals) constitute the prison itself and that is being termed by the researcher as "Social prison" and the individuals living in them are called "Social prisoners". Hence, the researcher has studied the four walls and tried to find the relationship between each of those walls with the social prison itself. However, the study is guided by the theory of break-up of mass culture by Mafessoli (1996) and Cova (1997), Weber (1946) class and status distinction theory and Fisher (1987) who also studied Weber in great depth and provide elaborate understanding of class and status [5] [8] [22] [23]. Although, while asking multiple questions from the respondents, it was found that, more than $60 \%$ of the respondents were under the age of 30 . It was also discovered through descriptive statistics that, while asking whether respondents are satisfied with the current status of living, interestingly, more than $80 \%$ of the respondents were found to be satisfied with their current status of living, while only $10 \%$ of them were dissatisfied with their current status of living. Moreover, when asked whether cultural restrictions have forced them to make concession in their lives in whatever the case may be, more than $60 \%$ of the respondents agreed that, cultural restrictions have pushed them to make concessions in their life at least once, while, more than $10 \%$ were disagreed with the idea. In the similar line of thought, while asking whether they are trapped in a rat race cycle or not, more than $70 \%$ nodded their heads in agreement that, they are trapped, while slightly more than $10 \%$ were disagreed with the notion. Although, the less number of respondents agreed, when it was being asked that, whether or not, they have sacrificed their most important goal or goals in order to satisfy the social norms/trends in the culture (urge to earn a lot of money/getting married/buying property or even supporting their family), surprisingly, more than $60 \%$ respondents agreed on the statement by saying that at least once, they have felt it, while, almost $14 \%$ disagreed by clicking that, they have not felt in that way either not frequently or not at all. It was found however, that more than $70 \%$ of the respondents agreed on the idea of the researcher that, at least once, they felt sad or depressed or unmotivated because of not living their life in a way, they wanted to live eventually. However, more than $10 \%$ were disagreed with the idea as well. In the final question of the questionnaire, when it was being asked, whether the respondents feel that, they are living in a social or 
cultural prison, almost $60 \%$ of the respondents agreed on the perception of the researcher that, at least once, they felt that, they are living in a cultural or social prison. However, $28 \%$ of them felt that, they are living in a prison but not frequently and only $13 \%$ of them argued that, they don't think that, they are living in any cultural or social prison at all.

Subsequently, when inferential test was conducted on the data in order to find the relationship between each of the independent and dependent variables, it was found that, there is a significant relationship between Material Acquisitions and Social Prisoner phenomenon in Pakistan because the $\mathrm{p}$ value was lesser than 0.05 and therefore, the first hypothesis of the study was accepted. Similarly, while finding the relationship between social status quo and social prisoner phenomenon in Pakistan, it was found through Pearson and Spearman results there is a significant relationship between Social Status Quo and Social Prisoner phenomenon in Pakistan because the $\mathrm{p}$ value was lesser than 0.05 and therefore, the second hypothesis of the study was also approved. Moreover, while finding the relationship between social envy and social prisoner, it was seen that, there is a significant relationship between Social Envy and Social Prisoner phenomenon in Pakistan because the $\mathrm{p}$ value was found to be lesser than 0.05 and therefore, the third hypothesis of the study was also accepted. In addition to that, while finding the connection between the final element of the social prison, social rituals and social prisoner, it was found to have significant relationship between the two, hence, the fourth hypothesis of this study was also accepted. However, all the fourth relationship was found to be having weak relationship between each of the independent variable (Material Acquisitions, Social Status Quo, Social Envy and Social Rituals) and dependent variable (social prisoner phenomenon in Pakistan). Finally, when all the elements of social prison were combined in order to depict a complete picture of a social prison and then finding its relationship with social prisoner, it was discovered ultimately that, there is a significant relationship between social prison and social prisoner phenomenon in $\mathrm{Pa}$ kistan. However, the strength of the relationship was found to be moderate through both tests as it was found to be near to $40 \%$ in both tests.

\section{Conclusion}

The social prisoner phenomenon is quite a new idea that is not explored and explained yet by any scholar in detail; hence, this research is fundamental, radical and quite important in its nature and significance. The social prison is actually an imaginary prison that is made up of four walls Material Acquisitions, Social Status Quo, Social Envy and Social Rituals. The researcher has tried to find the relationship between each of those walls and social prisoner phenomena as once, the relationship is found, this can be argued with some certainty that, individuals do live in the $21^{\text {st }}$ century not in real prison but an imaginary one. The study is guided by Mafessoli's (1996) break-up of mass culture theory and Cova (1997) who was greatly influenced by Mafessoli, studying neo-tribes extensively and eventually successfully dividing the concept of neo-tribes into two broader types: 
Temporal and Spatial [5] [8]. The study was also guided by Weber's (1946) class and status distinction theory and Fisher's (1987) understanding of status symbols [22] [23]. This research is based upon the philosophy of post-positivism as post-positivism has defined as it is important to understand positivism and then post-positivism. The positivist approach is closely related to the "scientific approach", that proclaims that there is only one single objective "truth" with verifiable patterns which can be predicted with certainty. Positivism, however, believes in "truth" which can be attained through methodical, rigorous and careful observation and is testified through repeatable methodologies. However, post-positivist is based upon the idea of fallibilism that implies that, absolute knowledge is impossible [46]. Hence, this research is based on post-positivism because: the phenomenon can possibly be revisited with new data and insights. It is basically a quantitative research and cross-sectional in nature as, the data is collected only at single point in time from respondents. The respondents are only those individuals working formally in any kind of field ranging from education to banking sector in Pakistan. The respondents are as diverse as possible in their socio-economic background and locality. However, the sample size is merely $170+$ respondents and the convenience sampling technique is used because of easy access to respondents and financial as well as time constraints.

However, the final results of this study were found through inferential statistics starting from approving Hypothesis 1 to Hypothesis 5. Therefore, it was found firstly that, there is a significant relationship between Material Acquisitions and Social Prisoner phenomenon in Pakistan because the $\mathrm{p}$ value was lesser than 0.05 and thus, the first hypothesis was accepted. However, the strength of relationship between the two variables was discovered to be weak. Furthermore, when the second and third hypotheses were considered, it was found that, there is a significant relationship between Social Status Quo and Social Prisoner phenomenon in Pakistan because the $\mathrm{p}$ value was lesser than 0.05 and therefore, the second hypothesis was approved, similarly, there is a significant relationship between Social Envy and Social Prisoner phenomenon in Pakistan because the $\mathrm{p}$ value was found to be lesser than 0.05 and therefore, the third hypothesis of the study was also accepted and the relationship found in both hypotheses was weak in nature. Finally, when the researcher tried to find the last relationship of the study, it was found that, there is a significant relationship between Social Rituals and Social Prisoner phenomenon in Pakistan because the $\mathrm{p}$ value was lesser than 0.05 and hence, the fourth and second last hypothesis was also accepted. However, the strength of relationship between the two variables can be considered weak. Subsequently, when all the independent variables are combined to make a concept of "Social Prison" and finding its relationship with the social prisoner phenomenon in Pakistan, it was uncovered that, there is a significant relationship between Social prison and social prisoner phenomenon in Pakistan with moderate strength. Hence, it can be concluded at the end that, those who are too much attached to material acquisitions, social status quo, social rituals and become the victim of social envy are living somehow a life of social prisoner be- 
cause, they live in a social prison whether knowingly or unknowingly.

\section{Practical Implications}

1) The concept of the social prisoner can open the door for new kind of research, that will focus on the problems and consequences emerged from the indulgence of materialistic products.

2) The social prisoner phenomenon will also enlighten the common audience regarding their inner decision making process and how that impacts on their life.

3) The results of this study would encourage the other researchers of social science to understand the human behavior and how that behavior is formed.

4) The concept will provide the foundation that can be used for further research in similar domain.

5) The concept will inform the common reader that, how their culture has influenced on them and how, they can get rid of from that influence.

\section{Conflicts of Interest}

The author declares no conflicts of interest regarding the publication of this paper.

\section{References}

[1] Pereraa, H.S.C. and Gunawardanab, T.S.L.W. (2014) Modern Consumerist Culture, Its Drawbacks and Benefits. Proceedings of the 3rd International Conference on Management and Economics, Vol. 26, 27.

[2] Stearns, P.N. (2001) Consumerism in World History: The Global Transformation of Desire. Routledge, London. https://doi.org/10.4324/9780203183236

[3] Hetherington, K. (1998) Expressions of Identity: Space, Performance, Politics. Sage Publications, London, New Delhi.

[4] Todd, D. (2012) You Are What You Buy: Postmodern Consumerism and the Construction of Self. Hohonu Academic Journal of University of Hawaii, 10, 48-50.

[5] Cova, B. (1997) Community and Consumption: Towards a Definition of the "Linking Value" of Product or Services. European Journal of Marketing, 31, 297-316. https://doi.org/10.1108/03090569710162380

[6] Sollors, W. (1989) The Invention of Ethnicity. Oxford University Press, Oxford.

[7] Mirosa, M. (2007) Neo-Tribal Consumption of Ideologies: Insights from New Social Movement Theory. ANZMAC Conference Proceedings, 2231-2237.

[8] Maffesoli, M. (1996) The Time of the Tribes: The Decline of Individualism in Mass Society. Sage, London.

[9] Newman, G. (1978) The Punishment Response. Lippincott, New York.

[10] Pollock, J.M. (2005) The Rationale for Imprisonment. The Philosophy and History of Prison. 17.

[11] Cross Jr., W.E. (1971) The Negro-to-Black Conversion Experience. Black World, 20, 13-27.

[12] Belk, R.W. (1985) Materialism: Trait Aspects of Living in the Material World. Journal of Consumer Research, 12, 265-280. https://doi.org/10.1086/208515 
[13] Scott, K. (2009) Terminal Materialism vs. Instrumental Materialism: Can Materialism Be Beneficial? Doctoral Dissertation, Oklahoma State University, Stillwater.

[14] Twitchell, J.B. (1999) Two Cheers for Materialism. The Wilson Quarterly, 23, 16-26.

[15] Windisch, L. and MacDermott, S. (2009) Materialistic Tendencies: Materialism and Psychological Well-Being in an Australian Adult Sample. Annual Conference of the Australia and New Zealand Marketing Academy, 1-8.

[16] O’Neill, J.H. (1997) The Golden Ghetto: The Psychology of Affluence. Affluenza Project.

[17] Kasser, T. (2002) The High Price of Materialism. The MIT Press, Cambridge. https://doi.org/10.7551/mitpress/3501.001.0001

[18] Arndt, J., Solomon, S., Kasser, T. and Sheldon, K. (2004) The Urge to Splurge: A Terror Management Account of Materialism and Consumer Behavior. Journal of Consumer Psychology, 14, 198-212. https://doi.org/10.1207/s15327663jcp1403_2

[19] Wright, R. (2000) Non-Zero: The Logic of Human Destiny. Vintage Books, New York.

[20] Kempen, V.L. (2003) Fooling the Eye of the Beholder: Deceptive Status Signaling among the Poor in Developing Countries. Journal of International Development. The Journal of the Development Studies Association, 15, 157-177. https://doi.org/10.1002/jid.973

[21] Siang, A.C. and Talib, M.A. (2011) An Investigation of Materialism and Undergraduates' Life Satisfaction. World Applied Sciences Journal, 15, 1127-1135.

[22] Weber, M. (1946) From Max Weber: Essays in Sociology. Oxford University Press, New York.

[23] Fisher, J.E. (1987) Social Class and Consumer Behavior: The Relevance of Class and Status. Advances in Consumer Research, Toronto, Volume 14.

[24] Kesic, T. and Rajh-Piri, S. (2003) Market Segmentation on the Basis of Food-Related Lifestyles If Croatian Families. British Food Journal, 105, 162. https://doi.org/10.1108/00070700310477112

[25] Lindquist, J.D. and Sirgy, M.J. (2009) Shopper, Buyer, and Consumer Behavior: Theory, Marketing Applications and Public Policy Implications. Atomic Dog/Cengage Learning, Cincinnati.

[26] Kaza, S. (2000) Overcoming the Grip of Consumerism. Buddhist-Christian Studies, 20, 23-42. https://doi.org/10.1353/bcs.2000.0013

[27] Scheler, M. (1961) Ressentiment. Free Press, New York.

[28] Schoeck, H. (1970) Envy: A Theory of Social Behavior. Translation by Glenny, M. and Ross, B., Harcourt, Brace, and World, New York.

[29] Foster, G.M., Apthorpe, R.J., Bernard, H.R., Bock, B., Brogger, J., Brown, J.K., Freeman, S.T., et al. (1972) The Anatomy of Envy: A Study in Symbolic Behavior [and Comments and Reply]. Current Anthropology, 13, 165-202. https://doi.org/10.1086/201267

[30] Kant, I. (1997) Lectures on Ethics. Cambridge University Press, Cambridge. https://doi.org/10.1017/CBO9781107049512

[31] Clanton, G. (2006) Jealousy and Envy. In: Handbook of the Sociology of Emotions, Springer, Boston, 410-442. https://doi.org/10.1007/978-0-387-30715-2_19

[32] Vohs, K.D., Wang, Y., Gino, F. and Norton, M.I. (2013) Rituals Enhance Consumption. Psychological Science, 24, 1714-1721.

https://doi.org/10.1177/0956797613478949 
[33] Winzeler, R.L. (2012) Anthropology and Religion: What We Know, Think, and Question. Rowman \& Littlefield, Lanham.

[34] Buckser, A. (1997) Ritual. In: Barfield, T., Ed., The Dictionary of Anthropology, Blackwell, Oxford, 410.

[35] Tannahill, R. (1995) Food in History. Three Rivers Press, New York.

[36] Rossano, M.J. (2012) The Essential Role of Ritual in the Transmission and Reinforcement of Social Norms. Psychological Bulletin, 138, 529-549. https://doi.org/10.1037/a0027038

[37] Sadian, S. (2018) Consumer Agency and Social Change: Experiences from Post-World War South Africa. Doctoral Dissertation, Universitat De Barcelona, Barcelona.

[38] Turner, J.C. and Tajfel, H. (1985) The Social Identity Theory of Intergroup Behavior. Psychology of Intergroup Relations, 5, 7-24.

[39] Banaji, M.R. and Prentice, D.A. (1994) The Self in Social Contexts. Annual Review of Psychology, 45, 297-332. https://doi.org/10.1146/annurev.ps.45.020194.001501

[40] Otnes, C. and Lowrey, T. (2004) Contemporary Consumption Rituals: A Research Anthology. Lawrence Erlbaum Associates, Mahwah. https://doi.org/10.4324/9781410610720

[41] Van Gennep, A. (1960) The Rites of Passage. University of Chicago Press, Chicago, (Original French Version (1909) Les Rites de Passage. Nourry, Paris) https://doi.org/10.7208/chicago/9780226027180.001.0001

[42] Turner, V.W. (1969) The Ritual Process: Structure and Anti-Structure. Routledge and Kegan Paul, London.

[43] Miller, T. (2007) Cultural Citizenship: Cosmopolitanism, Consumerism and Television in a Neoliberal Age. Canadian Journal of Sociology Online, 1-3.

[44] Friends of Earth (2013) Consumption and Identity. https://cdn.friendsoftheearth.uk/sites/default/files/downloads/consumption-identity -18135.pdf

[45] Bergami, M. and Bagozzi, R.P. (2000) Self-Categorization, Affective Commitment and Group Self-Esteem as Distinct Aspects of Social Identity in the Organization. British Journal of Social Psychology, 39, 555-577. https://doi.org/10.1348/014466600164633

[46] Phillips, D.C. and Burbules, N.C. (2000) Postpositivism and Educational Research. Rowman \& Littlefield, Lanham.

[47] Walliman, N. (2010) Research Methods: The Basics. Routledge, London and New York. https://doi.org/10.4324/9780203836071

[48] Baha, H. (2016) An Introduction of Descriptive Analysis, Its Advantages and Disadvantages (Online Assignment).

https://www.academia.edu/25307454/Title_An_Introduction_on_Descriptive_Anal ysis_Its_advantages_and_disadvantages

[49] Baddie, E. and Halley, F. (1995) Advantages in Social Research: Data Analysis Using SPSS for Windows. Pine Forge Press, a Sage Publications Company, Thousand Oaks.

[50] Adeyemi, T.O. (2002) Introductory Statistics for Educational Research Ado-Ekiti. Greenline Publishers, Brooklyn, 169-172. 